\title{
Aurora of October 22/23, 1958, at Rapid City, South Dakota
}

\author{
F. E. Roach* and E. Marovich*
}

(September 8, 1959)

\begin{abstract}
During the night of October 22/23, 1958, auroral activity at Rapid City, South Dakota, included (a) a visible aurora in the northern part of the sky and; (b) a "monochromatic" $(6300 \mathrm{~A})$ are through the zenith with an azimuth $12^{\circ}$ from east-west (geomagnetic). The intensity changes of the arc were independent of the changes in the visible aurora. It moved slowly southward during the night corresponding to a linear speed of about 8 meters per second if its height is 300 kilometers. It is suggested that it is a member of a family of monochromatic arcs which have until recently escaped detection because their red color makes them invisible even though intrinsically intense.
\end{abstract}

\section{Introduction}

In an earlier paper [1] ${ }^{1}$ we described a "monochromatic" (6300 A) arc at Fritz Peak. ${ }^{2}$ It was detached from and apparently independent of a visible aurora to the north.

According to Barbier [2] who has made a systematic study of $6300 \mathrm{~A}$ auroras at Haute Provence, they occur during about 10 percent of the time either as a general enhancement near the northern (geomagnetic) horizon or as ares with maxima in the eastern and western parts of the sky. In searching our records at both Fritz Peak and Rapid City, we find, in agreement with Barbier, that they are not infrequent. In this paper, we describe an aurora at Rapid City (longitude $103^{\circ} 18^{\prime} 50^{\prime \prime} \mathrm{W}$; latitude $44^{\circ} 01^{\prime} \mathrm{N}$; geomagnetic latitude $53^{\circ} \mathrm{N}$ ) on October $22 / 23$, 1958, which had a well-defined $6300 \mathrm{~A}$ arc near its southern edge.

\section{Observational Material}

During the night of October 22/23, 1958, the Rapid City photometer was making systematic sky surveys in the three colors - 5577, 6300, and $5893 \mathrm{~A}$. The surveys were in the form of zenith observations plus almucantar sweeps at zenith distances of $80^{\circ}$, $75^{\circ}, 70^{\circ}, 60^{\circ}$, and $40^{\circ}$. The complete cycle for the three colors required $15 \mathrm{~min}$. The spectral discrimination was by means of a birefringent filter [3]

In figure 1 (left) is shown an example of a set of the. original records. One of the striking features is the existence of sharp maxima or spikes on the $6300 \mathrm{~A}$ records near the east and west points of each of the sweeps, which are absent from the $5577 \mathrm{~A}$ records. ${ }^{3}$ When an isophote map is made of all the observations

*Central Radio Propagation Laboratory, National Bureau of Standards, Boulder, Colo.

1 Figures in brackets indicate the literature references at the end of this paper. 2 In this paper the word "monochromatic" is used to indicate that the $6300 \mathrm{~A}$ 2 In this paper the word "monochromatic"

radiation is predominant over the $5577 \mathrm{~A}$.
3 It is estimated that if $5577 \mathrm{~A}$ spikes as weak as $100 \mathrm{R}$ were present, they would ${ }^{3}$ It is estimater
be detectable. (right side of fig. 1) the spikes are seen to define a $6300 \mathrm{~A}$ arc extending across the sky in a general east-west direction. For both colors, there is activity near the northern horizon which developed into a bright aurora during the night.
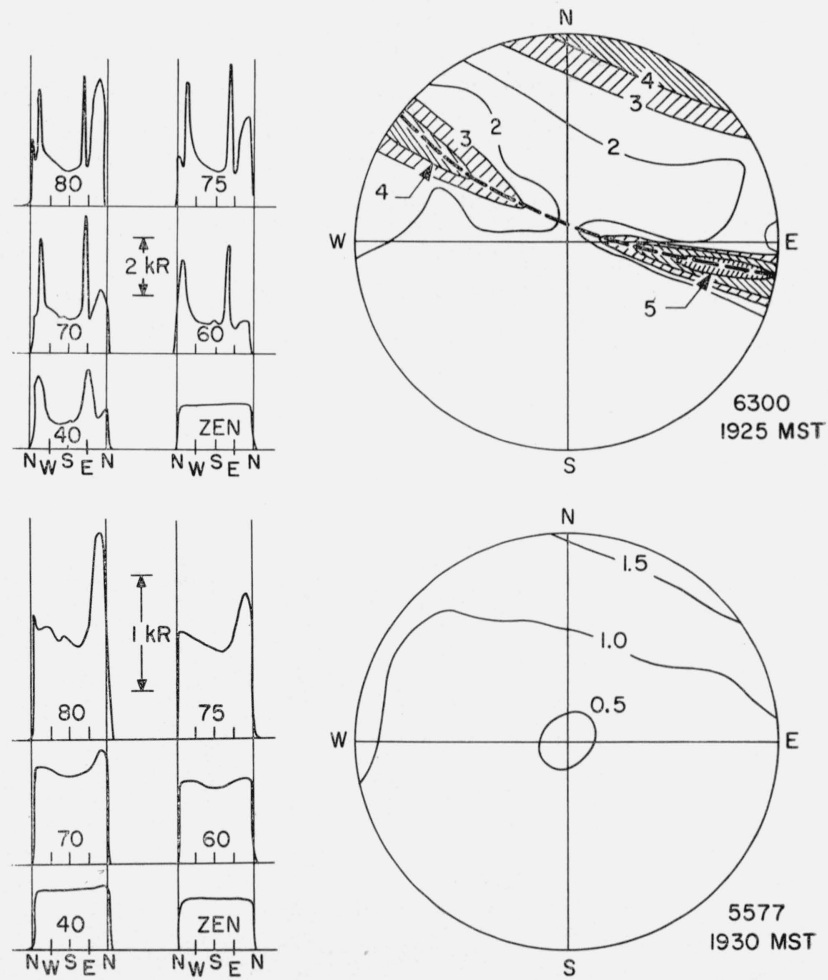

Figure 1. The original records (left) for $6300 A$ and $557 \% A$ at Rapid City for 1925 and 1930 m.s.t. on the night of October 22, 1958 .

Isophote maps of the sky (right) based on the original records. In drawing the isophote maps a height of $100 \mathrm{~km}$ was assumed for $5577 \mathrm{~A}$; of $300 \mathrm{~km}$ for $6300 \mathrm{~A}$. The unit of intensity is the kilorayleigh. 


\section{Evolution of the 6300 A Arc}

In figure 2 a pair of isophote maps shows a comparison of 5577 and $6300 \mathrm{~A}$ over the sky later in the night when the visible aurora was well developed in the northern part of the sky. The $6300 \mathrm{~A}$ arc is seen to have maintained its identity and discreteness independent of the visible aurora.
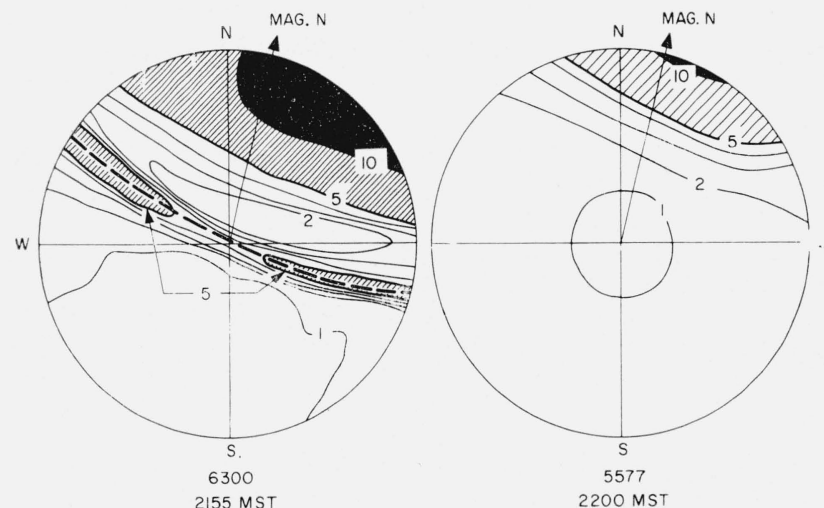

Figure 2. Isophote maps for $6300 A$ and $557 \mathrm{y} A$ for 2155 and 2200 m.s.t. after the development of an aurora over the northern part of the sky.

To illustrate the independence of the arc, we show in figure 3 the time variations of $6300 \mathrm{~A}$ intensity; (a) in the extreme north-northeast for the visible aurora and; (b) for the $75^{\circ} \mathrm{E}$ and $\mathrm{W}$ spikes of the arc. It is seen that the arc intensity seems unrelated to that of the northern aurora going steadily down, as the northern aurora goes through strong variations, often as much as 10 times the brightness of the arc.

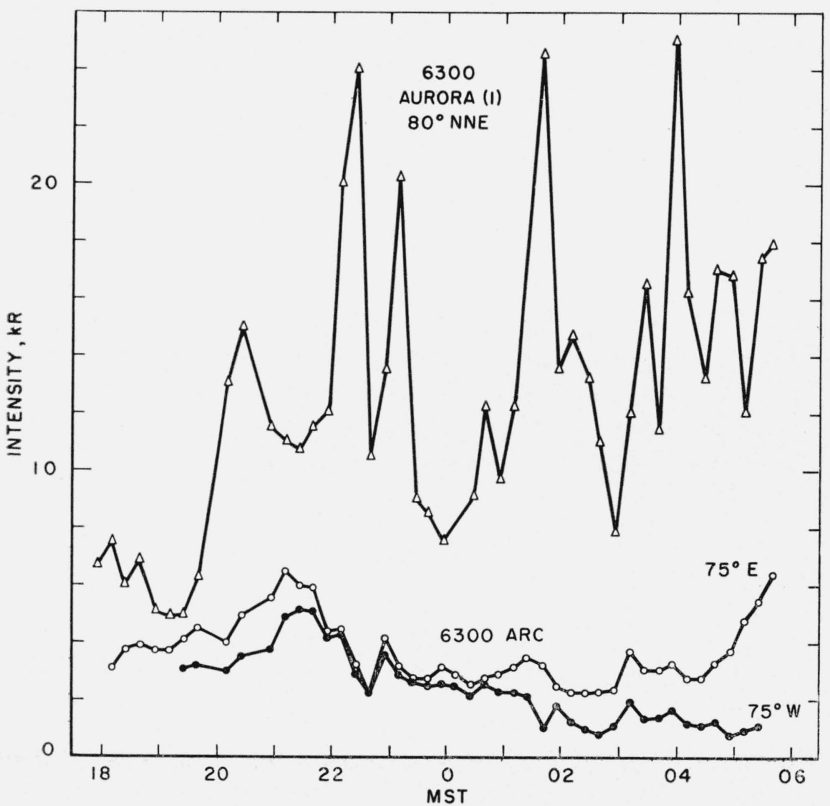

Figure 3. Comparison of $6300 \mathrm{~A}$ time variations in two parts of the sky-at $80^{\circ}$ zenith distance in the $N-N E$ and the spike in the eastern and western parts of the sky at $z=75^{\circ}$.
In figure 4 we show the position of the $6300 \mathrm{~A}$ arc for four different times during the night. It moves steadily southward, as shown also in figure 5 . From figure 5 we deduce a mean speed of $8 \mathrm{~m} / \mathrm{sec}$ for an assumed height of $300 \mathrm{~km}$. This compares with $6 \mathrm{~m} / \mathrm{sec}$ for the similar arc of September 29/30, 1957, at Fritz Peak [1]; $58 \mathrm{~m} / \mathrm{sec}$ for the $6300 \mathrm{~A}$ front at Sacramento Peak on February 10/11, 1958 (Manring and Pettit [4]); and $100 \mathrm{~m} / \mathrm{sec}$ for 5577 A airglow cells [5].

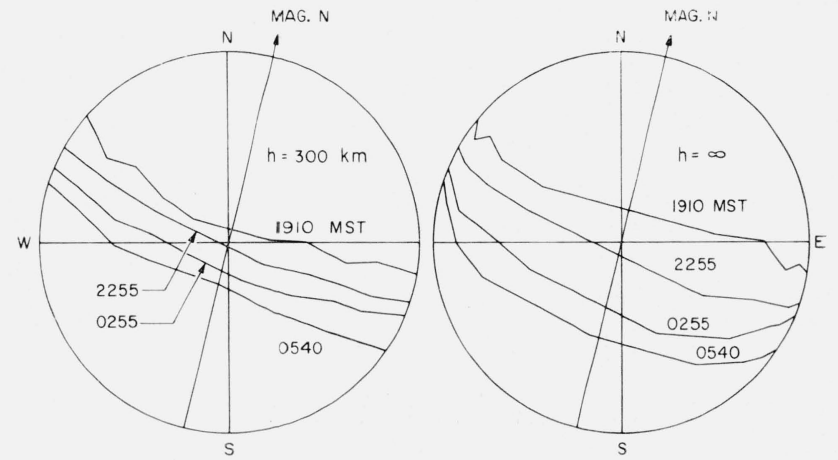

Figure 4. Movement of the 6300 A arc across the sky-as observed in the sky (right, $h=\infty$ ) and for an assumed height of $300 \mathrm{~km}$ (left).

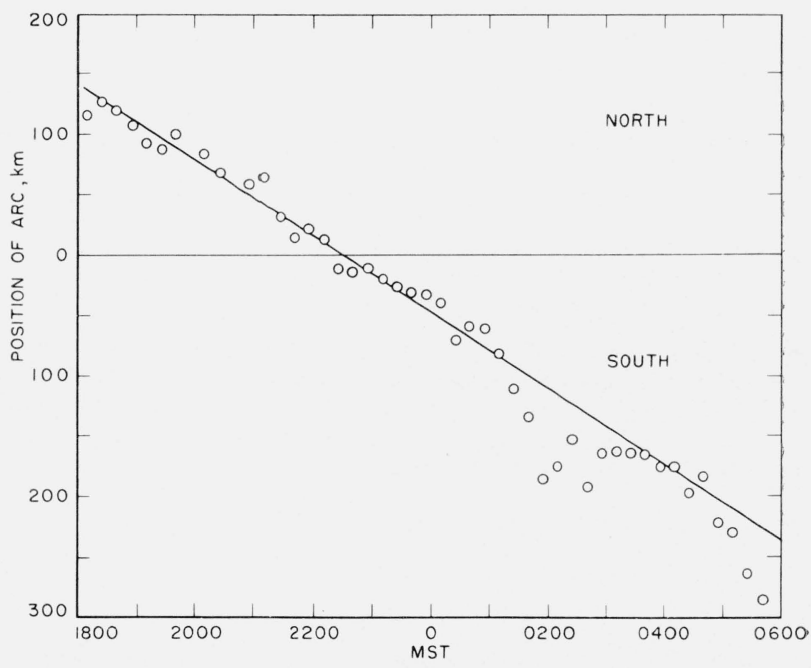

Figure 5. Position of 6300 A arc plotted against time for an assumed hoight of $300 \mathrm{~km}$.

\section{Tilt of the Arc}

In figures 1 and 2 we note that the arc seems to increase in intensity from the zenith to the horizon reminiscent of the so-called van Rhijn effect in the night airglow. This effect reverses during the night, however, as seen in figure 6 . The reversal occurs between 2210 and $2225 \mathrm{~m}$.s.t. Referring to figure 7 we note that this is the interval during which the arc crosses the zenith. We thus have the empirical facts that:

(a) When the arc is north of the zenith, it increases in brightness toward the horizon. 
(b) When the arc moves south of the zenith, it decreases in brightness toward the horizon.

This combination of facts is consistent with the assumption that the arc is inclined to the vertical along the magnetic lines of force (fig. 8). When the are is to the north of the zenith, the observer tends to look across the arc, which favors a higher

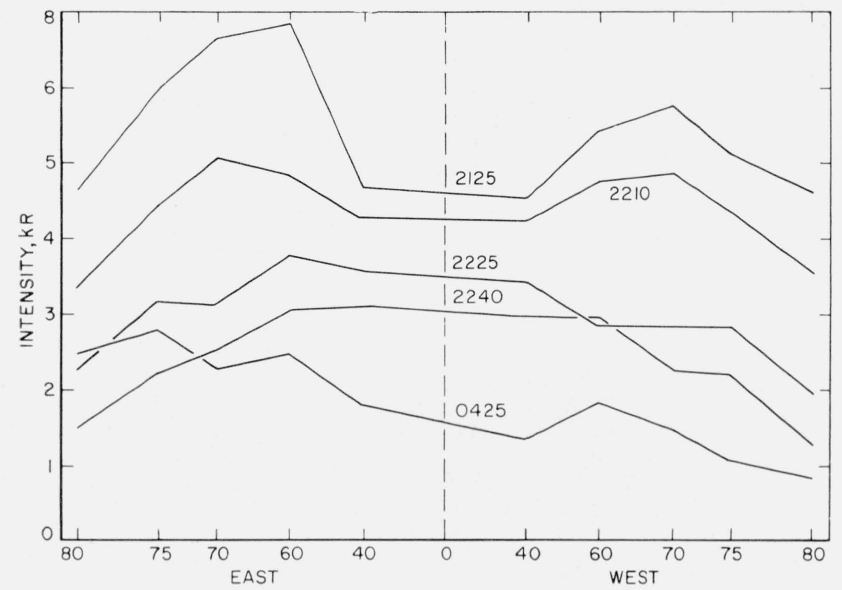

Figure 6. Intensity of $6300 \mathrm{~A}$ arc along its length as seen by the observer on the ground at Rapid City for several times during the night of October 22/23, 1958.

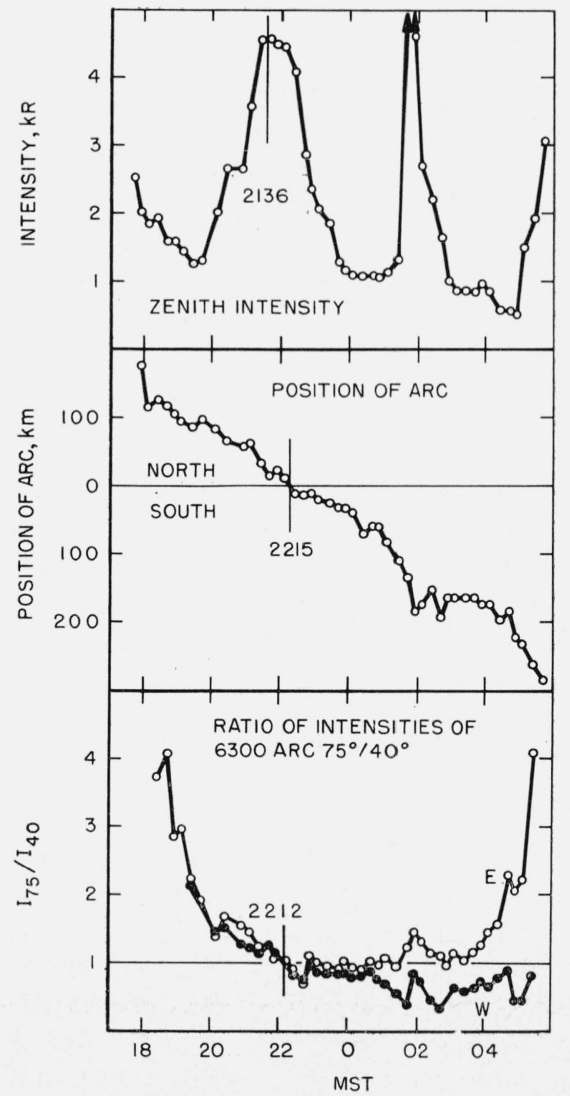

Figure 7. Changes with time of; (a) zenith intensity of $6300 \mathrm{~A}$, (b) position of the $6300 A$ arc, and, (c) the ratio $I_{75} / I_{40}$. intensity toward the horizon. As the arc moves to the south of the zenith, the observer looks more and more along the arc favoring a larger effective brightness near the zenith.

\section{Apparent Curvature of the Arc}

Figures 1, 2, and 4 all show that our method of plotting results in a curved arc which can be explained by assuming that the are follows a parallel of latitude (neither geographic nor geomagnetic, as we shall see in the next section). The amount of curvature should, in principle, give a value of the effective height of the arc, but very precise observations would be required to yield a reliable height by this method. A comparison of the observed curvature with that expected for assumed heights of 100,200 , and $300 \mathrm{~km}$ indicates that the he ght is at least $300 \mathrm{~km}$. Throughout this paper, we have assumed an effective height of $300 \mathrm{~km}$.

\section{Orientation of the Arc}

An inspection of figures 1, 2, and 4 shows clearly that the arc is oriented along the west-northwest to east-southeast direction. This is only approximately at right angles to magnetic north. Magnetic north at Rapid City is about $14^{\circ}$ east of geographic north; geomagnetic north is $11^{\circ} .3$ east of geographic north. We have estimated on working plots the direction of the perpendicular to each are and find the following:

Mean of 41 measures. $22^{\circ} .9$ east of geographic north Extremes _._. $24^{\circ} .7$ and $20^{\circ} .2$.

Thus, the observed are is inclined to magnetic parallels by an angle of about $9^{\circ}$ and to geomagnetic parallels by an angle of about $12^{\circ}$ in the sense that the western part is north and the eastern part south of the parallels.

It is of interest to note that this behavior is similar to that observed for polar auroral ares. For example, Vegard and Krogness [6] and Vegard [7] found an inclination of $10^{\circ}$ for arctic data from the first polar year. Jensen and Currie [8] report a mean inclination of $6^{\circ}$ for observations made in Canada. In both cases the sense of the inclination is the same as we have noted in the October $22 / 23$ arc at Rapid City.

\section{Southward Movement}

The hypothesis might be advanced that the southward movement of the are during the night is due to the rotation of the observer on the earth's surface under a fixed are oriented in a west-northwest, east-southeast direction. Calculation shows that a small angle of inclination (between $1^{\circ}$ and $2^{\circ}$ ) is sufficient to account for the observed movement of about $8 \mathrm{~m} / \mathrm{sec}$. Since the observed angle is much larger $\left(23^{\circ}\right)$, the hypothesis is not supported. 


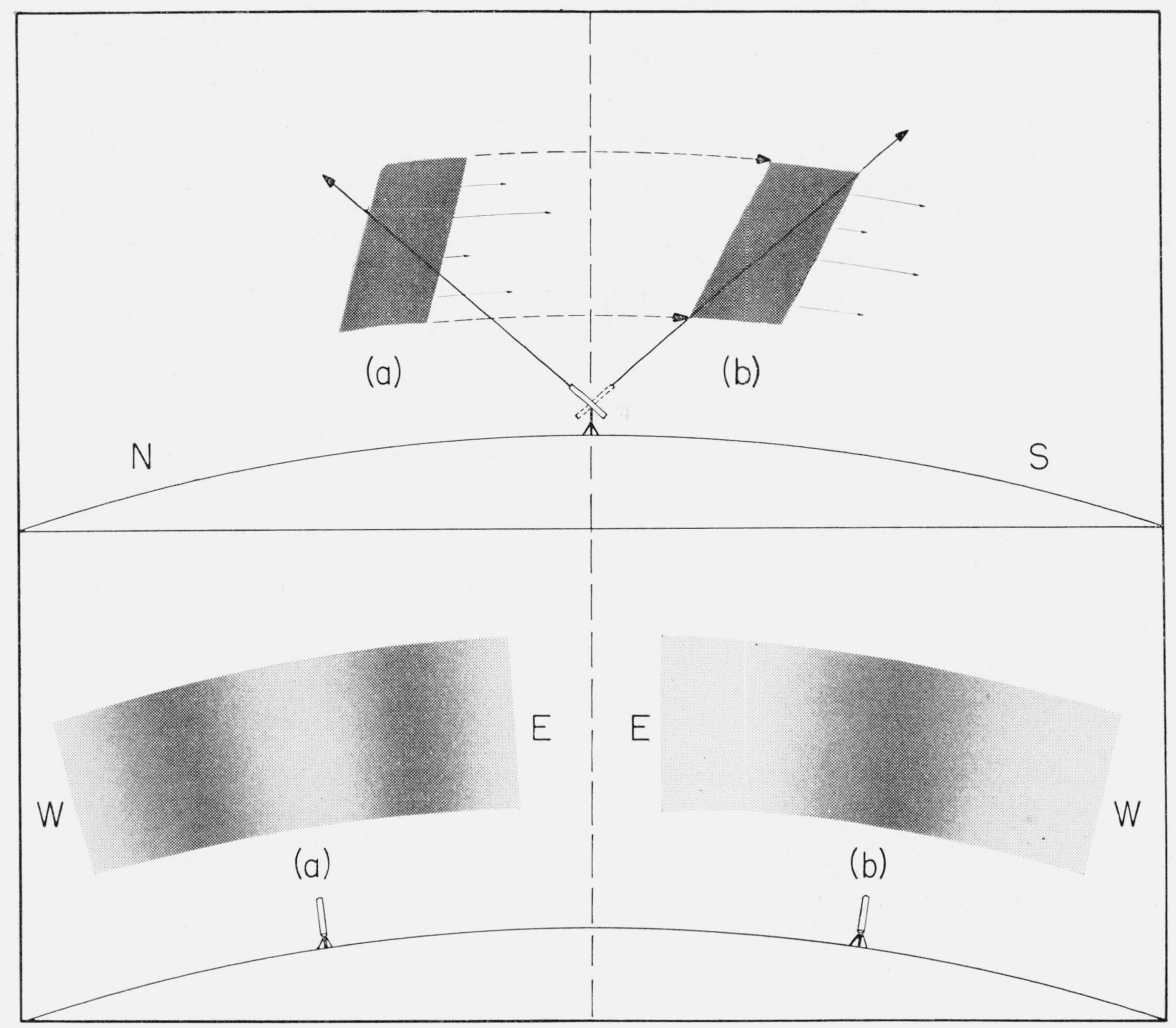

Figure 8. Section (above) and plan (below) views of the arc; (a) to the north of the observer and; (b) to his south.

The shading in the plan view corresponds to the observed zenith intensity dip when the arc is to the north (a) and the zenith intensity maximum when the are moves to the south.

\section{Discussion}

The evidence of this paper, of our earlier study [1], and of the work of Barbier at Haute Provence [2] suggests that there is a family of low latitude auroras with the following characteristics:

(a) The features are "monochromatic" (6300 A present; $5577 \mathrm{~A}$ absent). This implies that the excitation mechanism is sufficient to excite the oxygen atom to its ${ }^{1} \mathrm{D}$ state $(2.0 \mathrm{ev})$ but not to the ${ }^{1} \mathrm{~S}$ state $(4.2 \mathrm{ev})$.

(b) They occur at geomagnetic latitudes as low as $48^{\circ}$. The fact that they have not been observed overhead at Haute Provence $\left(\Phi=46^{\circ}\right)$ suggests that $48^{\circ}$ is actually the lower limit.

(c) They occur as arcs slightly inclined to the perpendicular to the earth's magnetic field.

(d) They may occur concurrently with visible auroras but they seem to be independent of the visible auroral activity both with regard to geographical position and absolute intensity.

(e) $6300 \mathrm{~A}$ ares have been observed in the southern hemisphere at Camden, Australia $\left(\Phi=42^{\circ} \mathrm{S}\right)$ by Duncan [9]. On September 5, 1958, the apex of such an arc was $74^{\circ}$ to the geomagnetic south. If the height is $300 \mathrm{~km}$, the arc would be $820 \mathrm{~km}$ or $7^{\circ} .5$ to the south, placing it at a geomagnetic latitude, $\Phi$, of $49^{\circ} .5$.
It is possible that $6300 \mathrm{~A}$ arcs are a general feature on the equatorial side of all auroras. If so, they would have escaped general detection since the visual threshold in the red is probably between 6 and 10 kilorayleighs. The two ares already studied by us had maximum intensities of 6 to $7 \mathrm{kR}$ and were detected only by means of a photometer and not visually. The color threshold for $6300 \mathrm{~A}$ is probably about $30 \mathrm{kR}$. We can therefore summarize the nature of the possible observations of such arcs.

\begin{tabular}{|c|c|c|}
\hline Class & $\begin{array}{c}\text { Absolute } \\
\text { intensity } \\
(\mathrm{kR})\end{array}$ & Nature of observation \\
\hline 1 & 1 to 6 & $\begin{array}{l}\text { Not visible; detectable only } \\
\text { with photometers }\end{array}$ \\
\hline $\begin{array}{l}2 \\
3\end{array}$ & $\begin{array}{l}6 \text { to } 30 \\
>30\end{array}$ & $\begin{array}{l}\text { Visible but no color } \\
\text { Visible as colored ares }\end{array}$ \\
\hline
\end{tabular}

Most of the historical data on auroral occurrence are based on visual observations, so class 1 ares (intensity $<6 \mathrm{kR}$ ) which might be expected to be the most frequent are just now being studied with monochromatic photometers.

It is possible that class 2 ares (intensity 6 to 30 $\mathrm{kR}$ ) mav be included in a compilation by Störmer [10]. Many of the features of certain arcs described 
by Störmer suggest similarities with the arc described in this paper. It is not possible to deduce whether Störmer's arcs were monochromatic $(6300$ A) or even approximately so. His observations are concentrated over southern Norway at $\Phi=56^{\circ}$.

The brighter class 3 arcs which appear red (6300 A) to the eye (intensity $>30 \mathrm{kR}$ ) seem to be very rare. Störmer [11] records only two such ares over southern Norway between 1911 and 1940. In a historical review, he lists nine between 1826 and 1872 and concludes "that red arcs very rarely occur, and only during years of great solar activity."

In our earlier paper [1] we suggested the possibility of some relationship between the $6300 \mathrm{~A}$ arcs and the newly discovered radiation belts. The arc discussed in the present paper corresponds to a dipole line of force cutting the magnetic equator at a distance of 2.8 earth radii from the center of the earth, just inside the inner edge of the outer radiation belt [12].

The authors are especially indebted to J. E. Cruz who was in charge of the observations at Rapid City during the International Geophysical Year and on the particular night under analysis in this paper. We have profited also by stimulating discussions with D. R. Bates, J. W. Chamberlain, and D. M. Hunten during a stay at the Yerkes Observatory during July-August 1959. The study was supported in part by the National Science Foundation during the I.G.Y. The visit to the Yerkes Observatory where the final discussion of the material was completed was sponsored by the Air Force Cambridge Research Center under Contract AF 19(604)-3044.

\section{References}

[1] F. E. Roach and E. Marovich, A monochromatic low latitude aurora, J. Research NBS 63D, 297 (1959)

[2] D. Barbier, L'activite aurorale aux basses latitudes, Ánn. Geophys. 14, 334 (1958)

[3] R. B. Dunn and E. R. Manring, Recording night sky photometer of high spectral purity, J. Opt. Soc. Am. $\mathbf{4 6}(\mathbf{8}), 572(1956)$

[4] E. R. Manring and H. B. Pettit, Photometric observations of the 5,577 A and 6,300 A emissions made during the aurora of February 10-11, 1958, J. Geophys. Research 64, 149 (1959)

[5] F. E. Roach, E. Tandberg-Hanssen, and L. R. Megill, Movements of airglow cells, J. Atmospheric and Terrest. Phys. 13, 122 (1958)

[6] L. Vegard and O. Krogness, The position in space of the aurora polaris from observations made at the Haldde Observatory, 1913-1914, Geofys. Publikasjoner 1, 1 (1920)

[7] L. Vegard, Recent results of northlight investigations and the nature of the cosmic electric rays, Phil. Mag. 42, 47 (1921)

[8] R. E. Jensen and B. W. Currie, Orientations of auroral displays in west-central Canada, J. Geophys. Research 46, $269(1953)$

[9] R. A. Duncan, Photometric observations of subvisual red auroral ares at middle latitudes, Australian J. Phys. 12, No. 2 (1959)

[10] Carl Störmer, Remarkable aurora - forms from southern Norway, I. Feeble homogeneous ares of great altitude, Geofys. Publikasjoner 11, No. 5 (1934-37)

[11] Carl Störmer, Remarkable aurora-forms from southern Norway, VII. Red patches and red ares, VIII. Some statistics on red aurorae in Norway, Geofys. Publikasjoner 13, 57 (1940-1944)

[12] J. Van Allen, C. E. Mellwain, and G. H. Ludwig, Radiation observations with satellite 1958 epsilon, J. Geophys. Research 64, 271 (1959)

Boulder, Colo.

(Paper 64D2-50) 